Personalidade Acadêmica Homenageada:

Augustus B. Cochran III (Agnes Scott College)

\title{
O IMPOSTO SOBRE GRANDES FORTUNAS COMO PROJETO PARA REDUÇÃO DA DESIGUALDADE SOCIAL NO BRASIL
}

\section{THE BIG FORTUNES TAX AS A PROJECT TO REDUCE SOCIAL INEQUALITY IN BRAZIL}

FABIANA BAPTISTA SILVA CARICATI

Advogada. Presidente da Comissão de Direito Tributário da Associação Brasileiro de Advogados. Membro do Instituto de Direito Tributário do Paraná e da Comissão de Direito Tributário da OABPR. Mestranda do Programa de Pós-Graduação Strictu Sensu em Direito Empresarial e Cidadania no Centro Universitário Curitiba Unicuritiba, Paraná. Pós-graduada em Direito Tributário pela Universidade Estadual de Maringá e em Contabilidade e Auditoria de Tributos pela FAE-Business School. Email: fabiana@caricati.adv.br

\section{RESUMO}

Este artigo procurou estudar o Imposto sobre Grandes Fortunas (IGF), tributo de competência da União, previsto na Constituição Federal, indicando os parâmetros favoráveis e contrários à sua incidência no cenário nacional. Partindo da análise bibliográfica e estudando o Direito Tributário Comparado, foi possível verificar que as análises financeiras e econômicas apontam que sua incidência levaria a um sistema tributário mais justo. Apesar destas análises objetivas, desde sua incorporação na Constituição Brasileira, em seu artigo 153, inciso VII, o IGF é o único dos sete tributos previstos sem regulamentação. Decorridos trinta anos da publicação da Constituição Cidadã e mesmo havendo alguns projetos de lei envolvendo o assunto do equilíbrio e reforma fiscal, o referido imposto, não consegue ser regulamentado. Não é 
Personalidade Acadêmica Homenageada:

Augustus B. Cochran III (Agnes Scott College)

desconhecido o fato de que a carga tributária nacional incide principalmente sobre o consumo da população menos favorecida e considerando a grave desigualdade social, o IGF se mostra como uma saída relevante, um instrumento distribuidor de riquezas, no intuito de ajuste fiscal e diminuição das disparidades, como de fato aponta a literatura de outros países, em especial na França. Pela relevância social do IGF, surgiu, então, o intuito da presente pesquisa para se buscar respostas para justificar o fato de sua não regulamentação no Brasil. Para a conclusão desta pesquisa, houve a necessidade de se estudar elementos fundantes derivados da Sociologia do Direito, se propondo a analisar a formação cultural e política da elite brasileira na época do neoliberalismo, como forma de verificar sua interferência para inviabilizar a regulamentação do IGF, já que os congressistas, quase sem exceção, seriam atingidos por essa tributação. Quando o legislador constituinte estabeleceu na Constituição um imposto sobre grandes fortunas, o qual visa alcançar a riqueza e contribuir para uma melhor distribuição de renda, não se esperava que o próprio Congresso que aprovou isso fosse o Congresso a não aprovar a regulamentação do IGF, tributo este que poderia ser o ponto de partida do equilíbrio fiscal e possibilidades de financiamentos voltados às políticas sociais.

PALAVRAS-CHAVE: Imposto; Fortuna; Brasil; Elite.

\section{REFERÊNCIAS}

AGUIAR, Simone Coelho; HISSA, Carolina Soares. Efetividade dos Direitos Sociais: O imposto sobre grandes fortunas como uma alternativa ao financiamento de políticas públicas. Congresso Nacional do Conpedi, Santa Catarina:2015. Disponível em https://www.conpedi.org.br/publicacoes/66fs/345/g5znv4pn/DEcd59qc9tCV8oe2.pdf. Acesso em 28 de agosto de 2018.

ALBUQUERQUE, Raíssa Carvalho Fonseca. Da omissão legislativa na instituição http://www.conteudojuridico.com.br/artigo,da-omissao-legislativa-na-instituicao-doimposto-sobre-grandes-fortunas,47163.html. Acesso em 20 de agosto de 2018.

ALVARENGA, Fabiana Cristina da Silveira. A Incidência do Imposto sobre Grandes 
Personalidade Acadêmica Homenageada:

Augustus B. Cochran III (Agnes Scott College)

Fortunas a partir de uma perspective voltada a um Sistema Tributário Equilibrado. V Encontro Internacional do Conpedi em Montevideu, Uruguai: 2016. Disponível em https://www.conpedi.org.br/publicacoes/9105o6b2//44qq457/d20hxyiaj82jqWn3.pdf. Acesso em 12 de maio de 2018.

BARROS, Rodrigo Rige da Silva. Carga Tributária, Função Social e Instituição do IGF. Disponível em: <http://www.conteudojuridico.com.br/pdf/cj038075.pdf>. Acesso em 12 de maio de 2018.

BRITO, Andrezza Souza de Oliveira; LARA, Caio Augusto Souza. Imposto sobre Grandes Fortunas: Regulamentação e Impactos Sociais. Revista Jurídica Percurso. v.3, no 22. Curitiba: 2017.

CARVALHO, Paulo de Barros. Curso de Direito Tributário. São Paulo: Saraiva, 1985.

CARVALHO, Pedro Humberto Bruno de. As discussões sobre a regulamentação do Imposto sobre Grandes Fortunas: a situação no Brasil e a experiência internacional. Disponível em http://www.ipea.gov.br/agencia/images/stories/PDFs/nota_tecnica/111230_notatecni cadinte7.pdf. Rio de Janeiro, outubro de 2011. IPEA. Acesso em 28 de agosto de 2018.

FISCHER, Octavio Campos; MACHADO, Luciano Marlon Ribas. Pacto Federativo em Crise: Uma Análise na Visão dos Municípios da Segurança Jurídica e da Dignidade Humana. Revista Jurídica, [S.I.], v. 53, n. 4, p. 233 - 254, out. 2018. ISSN 2316-753X. Disponível em: <http://revista.unicuritiba.edu.br/index.php/RevJur/article/view/3217/371371734>. Acesso em: 04 jun. 2019.

HARVEY, David. O Neoliberalismo. História e Implicações. São Paulo: Edições Loyola, 2008.

IBGE. Relatório de Condições de vida, desigualdade e pobreza no Brasil em 2017. Disponível em https://www.ibge.gov.br/estatisticasnovoportal/multidominio/condicoes-de-vida-desigualdade-e-pobreza/17270-pnadcontinua. html?edicao=20635\&t=conceitos-e-metodos. Acesso em 28 de agosto de 2018.

KHAIR, Amir. Imposto sobre Grandes Fortunas (IGF). Disponível em: $<$ http://www.ie.ufrj.br/aparte/pdfs/akhair190308_2.pdf>. Acesso em 28 de agosto de 2018.

LEITE, André Diego de Lima. O Imposto sobre Grandes Fortunas no Direito Comparado e na Lei Brasileira. Disponível em https://www.conjur.com.br/2015-out17/paulo-rosenblatt-fmi-recomenda-imposto-grandes-fortunas.Acesso em 12 de maio 
Personalidade Acadêmica Homenageada:

Augustus B. Cochran III (Agnes Scott College)

de 2018.

MACHADO, Hugo de Brito Machado. Curso de Direito Tributário. São Paulo: Malheiros, 1979.

NOGUEIRA, Ruy Barbosa. Curso de DireitoTributário. São Paulo: Saraiva, 1995.

OLMEDO, Luiza Bulhões. A maioria dos países desenvolvidos taxa ou já taxou sobre grandes fortunas. Disponível em: <http://www.sul21.com.br/jornal/a-maioriados-paises-desenvolvidos-taxa-ou-ja-taxou-as-grandes-fortunas/>. Acesso em 28 de agosto de 2018.

ROSENBLATT, Paulo. Até FMI recomenda imposto sobre grandes fortunas para redução de desigualdades. Disponível em https://www.conjur.com.br/2015-out17/paulo-rosenblatt-fmi-recomenda-imposto-grandes-fortunas. Acesso em 14 de setembro de 2018.

SABBAG, Eduardo. Manual de DireitoTributário. São Paulo: Saraiva, 2017.

SANTOS, Boaventura de Souza. Globalização e as Ciências Sociais. São Paulo: Cortez, 2002.

SOUZA, Jessé. Elite do Atraso. Da escravidão à Lava Jato. Rio de Janeiro: LeYa, 2017. 